• 研究报告・

\title{
黔西北石漠化地区两栖动物多样性及其生境选择
}

\author{
王存璐 陈 湤 ${ }^{*}$ 肖华张红梅 李林芝郭城陈静魏强 \\ (贵州师范大学喀斯特研究院, 国家喀斯特石漠化防治工程技术研究中心, 中国南方喀斯特生态环境学科创新引智基地, \\ 贵州省喀斯特山地生态环境省部共建国家重点实验培育基地，贵阳 550001)
}

\begin{abstract}
摘要：对两栖动物多样性及其生境选择的调查，可为两栖动物的保护提供基础性资料。我们于2018年9-10月、2019 年3-8月对贵州省毕节市撒拉溪石漠化综合治理示范区30个研究样方的两栖动物进行了调查, 共观察到两栖动物 5,688 只, 隶属 2 目 6 科 9 属 10 种。采用Shannon-Wiener多样性指数、Margalef丰富度指数、Pielou均匀度指数等分析 了不同等级石漠化区域中的两栖动物物种多样性, 采用Sorenson相似性系数、聚类分析等方法分析了群落的相似 性与差异性。结果显示: (1)云南小狭口蛙(Glyphoglossus yunnanensis)为优势种, 贵州疮䖵(Tylototriton kweichowensis)、 红点齿蟾(Oreolalax rhodostigmatus)、中华蟾蜍(Bufo gargarizans)、华西雨蛙(Hyla annectans)和昭觉林蛙(Rana chaochiaoensis)为常见种, 粗皮姬蛙(Microhyla butleri)、沼水蛙(Hylarana guentheri)、筠连臭蛙(Odorrana junlianensis) 和威宁蛙(Rana weiningensis)为稀有种。(2)无石漠化区域与潜在石漠化区域两栖动物物种数、个体数以及生境类 型较之其他 3 个等级石漠化区域更为丰富, 多样性指数、丰富度指数以无石漠化区域为最大。(3)无石漠化区域和 潜在石漠化区域之间、无石漠化区域和潜在石漠化区域分别与其他 3 个等级石漠化区域之间表现出较强的差异性。 研究表明, 喀斯特地区石漠化导致的生境差异是两栖动物分布差异的重要原因, 加强石漠化的生态治理是喀斯特 地区保护两栖动物的重要途径。
\end{abstract}

关键词: 石漠化; 喀斯特; 两栖动物; 多样性; 生境选择

\section{Diversity and habitat selection of amphibians in rocky desertification area in northwestern Guizhou}

Cunlu Wang, Hu Chen", Hua Xiao, Hongmei Zhang, Linzhi Li, Cheng Guo, Jing Chen, Qiang Wei

School of Karst Science, Guizhou Normal University, State Engineering Technology Institute for Karst Rocky Desertification Control, Overseas Expertise Introduction Center for Discipline Innovation, State Key Laboratory Incubation Base for Karst Mountain Ecology Environment of Guizhou Province, Guiyang 550001

\begin{abstract}
Amphibian protection can be encouraged through vital amphibian diversity and habitat selection studies. In September to October 2018 and March to August 2019, a total of 5,688 amphibians were recorded from the Bijie Salaxi rocky desertification comprehensive control area. The amphibians collected belonged to 2 orders, 6 families, 9 genera and 10 species. Various metrics were used to understand amphibian diversity in various environmental conditions such as the Shannon-Wiener diversity index, Margalef richness index and Pielou evenness index. Additionally, the Sorenson similarity coefficient and cluster analysis were used to analyze community similarity and difference. The results showed that: (1) Glyphoglossus yunnanensis was the dominant species, Tylototriton kweichowensis, Oreolalax rhodostigmatus, Bufo gargarizans, and Hyla annectans, Rana chaochiaoensis were the common species, Microhyla butleri, Hylarana guentheri, Odorrana junlianensis, and Rana weiningensis were the rare species. (2) The abundance of species, individuals, and habitat types increased in no rocky desertification areas and potential rocky desertification areas than in the other three grades of rocky desertification areas. Additionally, the diversity index and richness index were the largest in the non-rocky desertification areas. (3) Between no rocky desertification areas and potential rocky desertification areas; potential rocky desertification areas, and no rocky desertification areas showed strong differences with the other three grade areas. This study shows rocky desertification habitat differences
\end{abstract}

收稿日期: 2019-11-06; 接受日期: 2020-03-11

基金项目: 国家重点研发计划(2016YFC0502601)

* 通讯作者 Author for correspondence. E-mail: gy_chenhu@163.com 
in karst areas is important to distribution differences among amphibians, and strengthening the ecological control of rocky desertification is an important way to protect amphibians in karst areas.

Key words: rocky desertification; karst; amphibians; diversity; habitat selection

长期以来, 生物多样性的保护被认为是保护生 态环境、降低物种灭绝速率、促进可持续发展、保 障生态安全的重要措施(王建英等, 2012; 冯晓娟, 2019)。两栖动物由于独特的生活史周期、特殊的生 理学特性、直观的行为反应, 与其他野生动物相比 对环境变化更敏感, 是生态系统状况是否良好的生 物指示器(Mouchet et al, 2007; 姚明灿, 2014 ${ }^{\circledR}$ )。具 有不同生态特征的两栖动物对不同生境的偏好程 度有所不同(周绍春, 2016), 其生境选择行为可在一 定程度上反映生境之间的差异(杨维康, 2000)。因此, 在特定生态系统中研究两栖动物多样性及其生境 选择规律, 对目标生物的保护及生态系统的评价具 有实际意义。

以贵州省来说，2005-2020年间的两栖动物资 源调查大都位于生境条件优越、生境类型比较丰富 且相关部门以及周围居民对于动植物资源保护较 为重视的自然保护区(王延斌, 2005, 2010; 陈继军 等, 2007; 魏刚等, 2007; 徐宁等, 2008; 戴诗贵等, 2010; 张永宏等, 2012; 李仕泽等, 2015, 2017; 黄静 等, 2016; 吕敬才等, 2017a, b; 姚正明等, 2018), 而 对于喀斯特石漠化地区两栖动物资源的调查报道 几乎没有。石漠化作为喀斯特地区独特的生态系统 退化现象, 其发生与发展会造成植被结构单一、生 态系统简单化, 进而导致生物多样性下降(陈吘等, 2011), 因此, 本研究对贵州省毕节市撒拉溪石漠化 综合治理示范区(以下简称毕节撒拉溪示范区)两栖 动物物种多样性及其生境选择进行调查, 旨在为喀 斯特石漠化地区两栖动物及其栖息地的保护提供 科学依据。

\section{1 研究区概况}

毕节撒拉溪示范区 $\left(105^{\circ} 01^{\prime} 12^{\prime \prime}-105^{\circ} 08^{\prime} 38^{\prime \prime} \mathrm{E}\right.$, $\left.27^{\circ} 11^{\prime} 09^{\prime \prime}-27^{\circ} 17^{\prime} 28^{\prime \prime} \mathrm{N}\right)$ 位于乌江上游六冲河流域、 毕节市西部的撒拉溪镇和野角乡境内。该区属于亚 热带季风湿润气候, 冬春季节温和少雨, 夏秋季节

(1) 姚明灿 (2014) 中国两栖动物地理分布格局研究. 硕士学位论文, 中 南林业科技大学, 长沙.
湿热多雨, 多年平均气温 $12.8{ }^{\circ} \mathrm{C}, \geq 10{ }^{\circ} \mathrm{C}$ 年积温 $3,717^{\circ} \mathrm{C}$, 年降水量 $984.4 \mathrm{~mm}$, 降水时空分布不均, 降雨集中在夏季7-9月, 占全年降水量的52.6\%。土 壤以黄壤为主, 部分地区有黄棕壤和石灰土。示范 区总面积8,627.2 ha, 海拔1,200-1,600 m, 属于喀斯 特高原山地生态环境, 其中喀斯特面积 6,406.1 ha, 占总面积的74.3\%。根据熊康宁等(2002)制定的石漠 化等级划分标准，该示范区无石漠化区域1,667.2 ha (占示范区总面积的19.3\%)、潜在石漠化区域1,087.2 ha (12.6\%)、轻度石漠化区域2,228.9 ha (25.8\%)、中度 石漠化区域1,250.0 ha (14.5\%)、强度石漠化区域 172.9 ha (2.0\%)。经调查, 该示范区自然条件多样, 植物资源丰富, 植被以亚热带针阔叶混交林和落叶 阔叶林为主。区域内共有植物 720 种, 隶属133科437 属, 主要是以火棘属(Pyracantha)、栒子属(Cotoneaster)、栋属(Quercus)、青冈属(Cyclobalanopsis)、杜 鹃属(Rhododendron)等为主的藤刺灌从。

\section{研究方法}

\section{1 调查时间与方法}

根据研究区地形地貌特征、石漠化等级分布特 征选择合适的样方, 样方标准为半径 $100 \mathrm{~m}$ 的圆形, 每个石漠化等级选定6个样方, 总计 30 个样方(图1)。 使用样线法分别于2018年9-10月、2019年3-8月对 30 个样方的两栖动物进行调查, 每个样方具体调查 时间及两栖动物种类、数量见附录 1 。每次调查始 于日落后 $30 \mathrm{~min}$ 内, 一般为晚上 19:30-0:30。使用强 光手电筒对样点范围内的两栖动物进行搜寻, 并结 合声音进行方位判断。对搜寻到的两栖动物进行拍 照记录, 同时记录物种类别、个体数量、生存环境 等信息。若遇到无法辨认的两栖动物物种, 则捕捉 1 个个体带回室内进行鉴定。物种鉴定根据《中国动 物志: 两栖纲》 (费梁等, 2006, 2009a, b)、《中国两 栖动物及其分布彩色图鉴》(费梁等, 2012)和中国两 栖类数据库(http://www.amphibiachina.org/)进行。

\section{2 生境划分}

根据《中国动物志: 两栖纲》、《中国两栖动物 


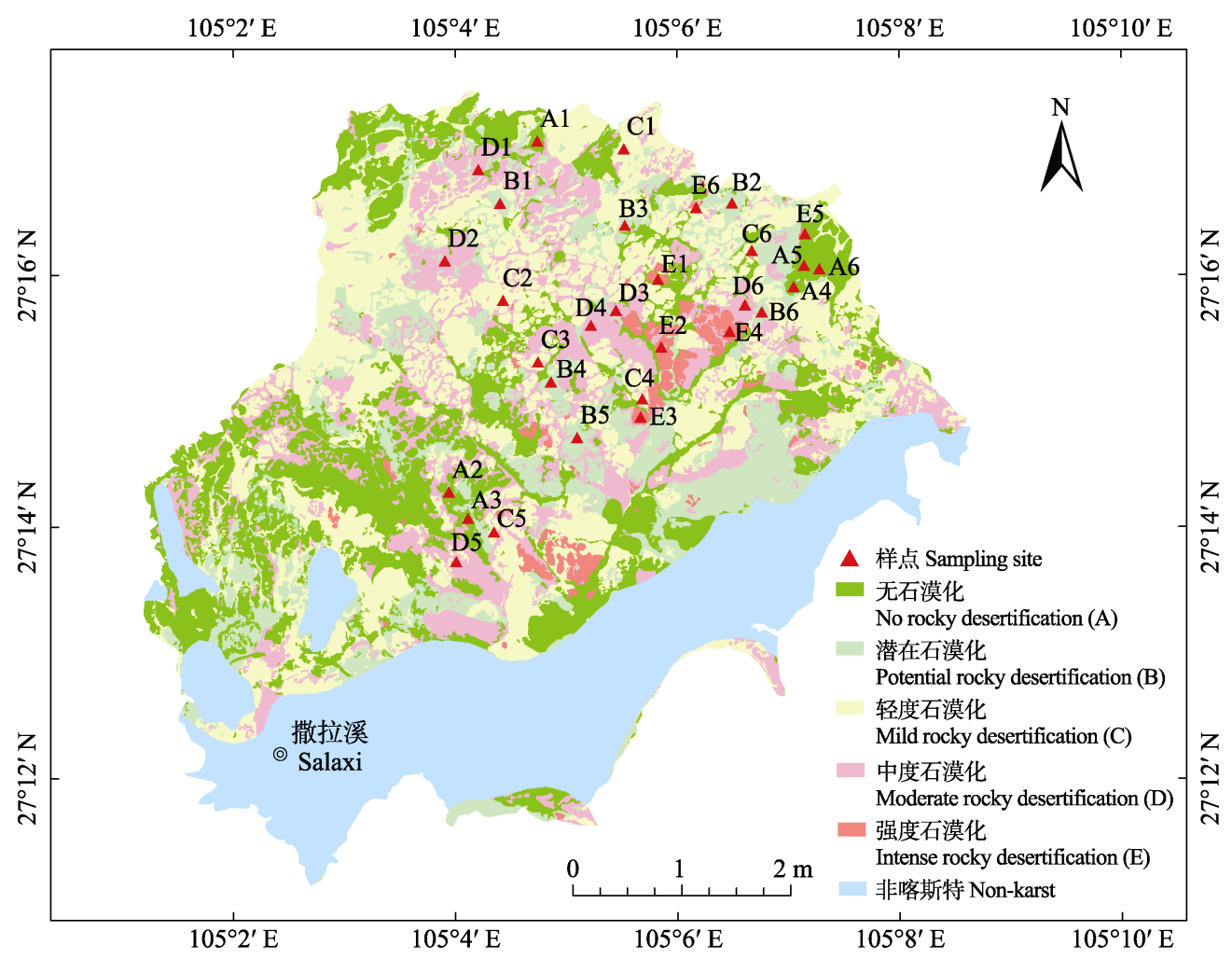

图1 毕节市撒拉溪石漠化综合治理示范区两栖动物研究样点分布图

Fig. 1 Distribution of amphibian study sampling sites in Bijie Salaxi rocky desertification comprehensive control area

及其分布彩色图鉴》和中国两栖类数据库中对两栖 动物各种生存环境的界定, 以及毕节撒拉溪示范区 地质地貌类型和人类活动痕迹, 将该地区两栖动物 栖息的生境类型划分为 15 种，分别是人工林、灌丛、 草地、沼泽湿地、溪流、天然湖泊、人工池塘、临 时水域、石缝、水洞、旱洞、耕地、撂荒地、道路、 房舍。其中, 无石漠化区域包括所有的15种生境类 型; 潜在石漠化区域包括除沼泽湿地和溪流外的其 余13种生境; 轻度石漠化区域包括灌丛、草地、人 工池塘、临时水域、石缝、旱洞、耕地、撂荒地、 道路和房舍10种生境; 中度石漠化区域包括草地、 人工池塘、临时水域、石缝、旱洞、撂荒地、道路 和房舍8种生境; 强度石漠化区域包括草地、临时水 域、石缝、旱洞、撂荒地和道路6种生境。

\section{3 数据处理}

多样性分析采用以下指数 (马克平和刘玉明, 1994):

Shannon-Wiener多样性指数:

$$
H^{\prime}=-\sum_{\mathrm{i}=1}^{\mathrm{s}} P_{i} \ln P_{i}
$$

式中, $P_{i}$ 为种i的个体数占总个体数的比例; 同时, $P_{i}$ 可认定为优势度值, $P_{i}$ 大于 $10 \%$ 时, 可认定为优势种; $P_{i}$ 介于 $1 \%-10 \%$, 可认定为常见种; $P_{i}$ 小于 $1 \%$, 可认 定为稀有种。

Margalef丰富度指数:

$S R=(S-1) / \ln N$

Pielou均匀度指数:

$$
J=H^{\prime} / \ln N
$$

相似性分析采用以下指数(马克平等, 1995):

Sorenson相似性系数:

$$
C=2 \mathrm{j} /(a+b)
$$

式中, $S$ 为种数, $N$ 为个体总数, $j$ 为两区域共有物种 数, $a 、 b$ 分别为两区域各自物种数。

采用聚类分析方法, 即将各样方中两栖动物物 种数和个体总数作为因变量代入 $Q$ 型聚类分析中, 通 过欧氏距离法将所有样方进行分类(李贲等, 2017)。 数据处理在Excel 2016、SPSS 22中进行。

\section{3 结果}

\section{1 两栖动物物种组成}

在2018年9-10月、2019年3-8月对毕节撒拉溪 
示范区 30 个样方的调查中, 共记录 5,688 只两栖动 物个体，隶属于 2 目6科9属 10 种(附录2)。其中云南小 狭口蛙(Glyphoglossus yunnanensis)为优势种, 占所 调查到的两栖动物总个体数的 $76.53 \%$ 。贵州疮螈 (Tylototriton kweichowensis)、红点齿蟾(Oreolalax rhodostigmatus)、中华蟾蜍(Bufo gargarizans)、华西 雨蛙(Hyla annectans)和昭觉林蛙(Rana chaochiaoensis)为常见种, 分别占所调查到的两栖动物总个 体数的 $8.98 \% 、 3.01 \% 、 2.88 \% 、 2.34 \%$ 和 $5.68 \%$; 粗 皮姬蛙(Microhyla butleri)、沼水蛙(Hylarana guentheri)、笏连臭蛙(Odorrana junlianensis)和威宁蛙 (Rana weiningensis)为稀有种, 分别占所调查到的 两栖动物总个体数的 $0.33 \% 、 0.14 \% 、 0.02 \%$ 和 $0.09 \%$ 。

区系组成上, 该区两栖动物以东洋界为主, 威 宁蛙属东洋界西南区物种, 华西雨蛙属东洋界华南 区和西南区共同分布种, 贵州病螈、红点齿蟾、云 南小狭口蛙、筠连臭蛙属东洋界华中区和西南区共 同分布种, 粗皮姬蛙、沼水蛙、昭觉林蛙属东洋界 华中区、华南区和西南区共同分布种，中华蟾蜍属 古北界和东洋界广布种。生态类型以陆栖静水型为 主，占总物种数的 $60 \%$; 陆栖流水型有 3 种, 分别为 红点齿蟾、筠连臭蛙和威宁蛙; 仅华西雨蛙 1 种为树 栖型。10种两栖动物中, 贵州疮螈属国家二级保护 动物, 其濒危等级为易危, 同被列为易危等级的还有 红点齿蟾、笏连臭蛙和威宁蛙; 其余6种为无危。

\section{2 两栖动物多样性}

不同等级石漠化区域的两栖动物多样性分析 结果表明(表1): Shannon-Wiener多样性指数表现为 无石漠化区域 $>$ 轻度石漠化区域 $>$ 中度石漠化区 域 $>$ 强度石漠化区域 $>$ 潜在石漠化区域, Margalef 丰富度指数表现为无石漠化区域 $>$ 潜在石漠化区 域 $>$ 轻度石漠化区域 $>$ 强度石漠化区域 $>$ 中度 石漠化区域, Pielou均匀度指数表现为中度石漠化 区域 $>$ 强度石漠化区域 $>$ 轻度石漠化区域 $>$ 无 石漠化区域 > 潜在石漠化区域。

\section{3 两栖动物群落相似性}

利用所调查的研究区两栖动物物种数量和个 体数量, 对分属不同石漠化等级的 30 个样方进行聚 类分析，在类间距离5-10的区间将所有研究样点分 为4组(图2)。

I组: 共有 26 个样方, 包含所有 6 个强度石漠化 样方、6个中度石漠化样方、 6 个轻度石漠化样方、
3 个潜在石漠化样方和 5 个无石漠化样方。

II组: 仅 1 个样方, 即无石漠化样方 $\mathrm{A} 1$ 。在该样 方中观察到249只贵州疮螈、28只中华蟾蜍，分别占 到无石漠化区域此两种总个体数的 $91.54 \%$ 和 $56.72 \%$, 且在该样方中还观察到2只沼水蛙，而其他 无石漠化样方中并未发现沼水蛙。

III组：含 2 个样方, 即潜在石漠化样方B3和B4。 在样方B3中观察到云南小狭口蛙1,594只、两栖动物 物种 5 种，样方 $\mathrm{B} 4$ 中观察到云南小狭口蛙 1,365 只、 两栖动物物种 6 种, 远高于I组中的 3 个潜在石漠化 样方。

IV组: 仅1个样方, 即潜在石漠化样方B5。虽然 该样方中观察到两栖动物6种，但云南小狭口蛙个 体数为 1,044 只, 较之I组中的 3 个潜在石漠化样方个 体数多, 而较之III组中的 2 个潜在石漠化样方个体 数稍少, 故自成一类。

群落相似性分析结果显示, 30 个样方中两栖动物 相似性系数处于 $0.00-1.00$ 之间, 其中无石漠化区域 和潜在石漠化区域之间、无石漠化区域和潜在石漠 化区域分别与其他 3 个石漠化等级之间表现出较强 的差异性(表2)。由于轻度石漠化区域、中度石漠化 区域和强度石漠化区域每个样方中两栖动物物种 数单一, 其相互之间的相似性指数大多呈极值状态。

\section{4 两栖动物分布与生境选择}

根据调查, 15种生境的主要特征见附录3, 不同 等级石漠化区域中包含的生境类型与有两栖动物 出现的生境类型对比见表 3 , 不同种类两栖动物在 各样方中栖息的生境类型见附录 4 。在无石漠化区 域所包含的15种生境中，两栖动物出现于12种生境; 在潜在石漠化区域所包含的13种生境中，两栖动物 出现于 10 种生境, 在轻度石漠化区域所包含的 10 种 生境中, 两栖动物出现于 3 种生境; 在中度石漠化 区域所包含的 8 种生境中，两栖动物出现于 4 种生境; 在强度石漠化区域所包含的6种生境中, 两栖动物 仅出现于1种生境。

两栖动物在不同生境中的分布见表4。利用每 个两栖动物物种在某一生境中分布的个体数与该 两栖动物物种总个体数之比来表征两栖动物对于 生境的选择， < 1\%为分布稀少，1\%-10\%为分布一般， $>10 \%$ 为分布较多。其中, 贵州病螈主要分布在天然 湖泊、人工池塘和临时水域了种生境, 红点齿蟾主要 分布在沼泽湿地和水洞2种生境, 中华蟾蜍主要分 
表1 毕节市撒拉溪石漠化综合治理示范区不同等级石漠化区域两栖动物多样性指数

Table 1 Diversity index of amphibians in rocky desertification areas with different grades in Bijie Salaxi rocky desertification comprehensive control area

\begin{tabular}{llll}
\hline $\begin{array}{l}\text { 石漠化等级 } \\
\text { Grade of rocky }\end{array}$ & $\begin{array}{l}\text { Shannon-Wiener多样性指数 } \\
\text { Shannon-Wiener diversity index }\end{array}$ & $\begin{array}{l}\text { Margalef丰富度指数 } \\
\text { Margalef richness index }\end{array}$ & $\begin{array}{l}\text { Pielou均匀度指数 } \\
\text { Pielou evenness index }\end{array}$ \\
\hline 无石漠化 No rocky desertification & 1.645 & 0.982 & 0.791 \\
潜在石漠化 Potential desertification & 0.414 & 0.954 & 0.199 \\
轻度石漠化 Mild rocky desertification & 0.974 & 0.721 & 0.887 \\
中度石漠化 Moderate rocky desertification & 0.688 & 0.334 & 0.993 \\
强度石漠化 Intense rocky desertification & 0.673 & 0.621 & 0.971 \\
\hline
\end{tabular}

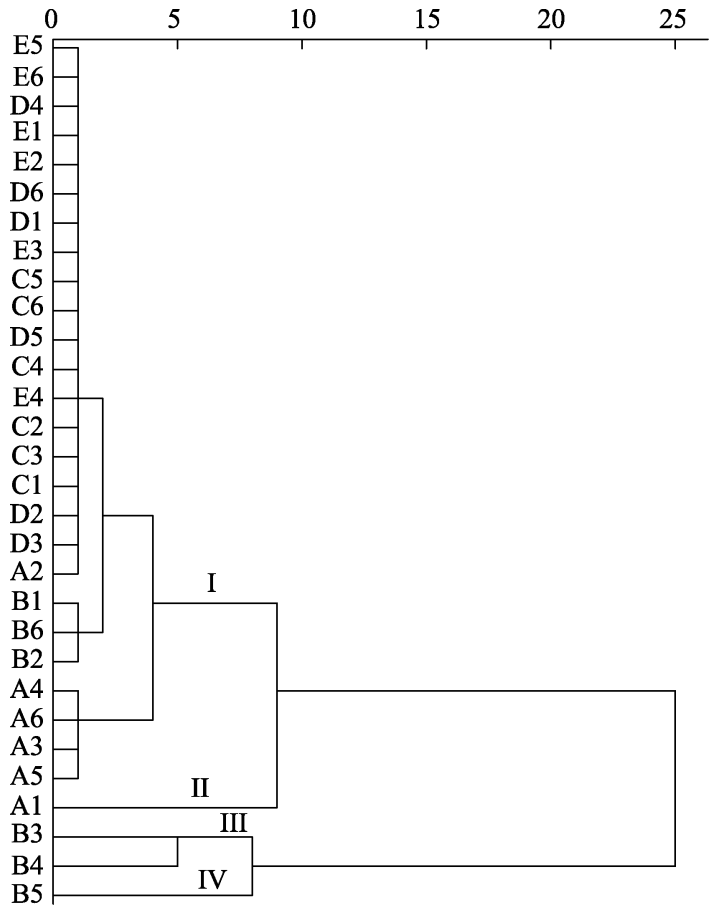

图2 毕节市撒拉溪石漠化综合治理示范区30个样方两栖群 落聚类结果。A: 无石漠化; B: 潜在石漠化; C: 轻度石漠化; D: 中度石漠化; E: 强度石漠化。

Fig. 2 Clustering results of amphibian communities in 30 quadrats in Bijie Salaxi rocky desertification comprehensive control area. A, No rocky desertification; B, Potential rocky desertification; C, Mild rocky desertification; D, Moderate rocky desertification; E, Intense rocky desertification.

布在人工池塘和临时水域2种生境, 华西雨蛙主要 分布在沼泽湿地、人工池塘和临时水域3种生境, 云 南小狭口蛙主要分布在人工池塘和临时水域2种生 境, 粗皮姬蛙主要分布在草地和临时水域2种生境, 沼水蛙主要分布在草地、天然湖泊和临时水域3种 生境, 筠连臭蛙主要分布在天然湖泊 1 种生境, 昭 觉林蛙主要分布在沼泽湿地、天然湖泊、人工池塘 和临时水域 4 种生境, 威宁蛙主要分布在灌从和草 地2种生境。

\section{讨论}

\section{1 喀斯特石漠化地区两栖动物物种组成对比}

根据贵州省动物地理区划(伍律等, 1987; 魏刚 等, 1989), 毕节撒拉溪示范区属于黔西高原中山省, 据中国两栖类数据库和最新资料显示(Wang et al, 2019), 目前该地理区内已发现两栖动物33种, 占贵 州省两栖动物总数的 $38.82 \%$ 。本研究中两栖动物仅 占黔西高原中山省两栖动物总数的 $30.30 \%$, 相较于 贵州其他地区，物种种类明显偏少，这是由于毕节 撒拉溪示范区作为典型喀斯特高原山地地貌类型, 石漠化较为严重，特殊的地上地下二元结构使得地 表水资源匮乏, 生态系统功能逐渐衰退; 加之当地 政府及居民生态环境保护意识欠缺, 不合理的人为 干扰如植被破坏、道路和房舍修建、采矿场建设、 环境污染等加剧了两栖动物栖息地的破碎化, 多种 原因共同作用影响了两栖动物的生存和分布, 导致 研究区生物多样性偏低。

在所调查到的 10 种两栖动物中, 有 4 种处于易 危状态, 分别为贵州疮螈、红点齿蟾、筠连臭蛙和 威宁蛙。贵州疮螈属于国家二级保护动物, 该物种 大多生活于阴暗潮湿的有灌从杂草伴生的土洞、石 缝、小水塘等地, 多在雷雨天气进行繁殖。研究区 内有较多适合贵州疮缐栖息和繁殖的场所, 且在其 繁殖季节雷雨天气较为频繁, 因此贵州疮螈在研究 区属于常见种, 但其保护现状不容乐观。因为该物 种行动较为缓慢, 研究区大范围筑路工程的开展导 致其道路致死率较高。红点齿蟾在研究区内也属于 常见种, 因为研究区存在一定范围的天然沼泽湿地, 当地居民多在湿地水源点修建饮用水引水空井, 黑 暗、深水和适于隐藏的环境有利于红点齿蟾的繁殖 和生存; 加之研究区特殊的地质地貌条件造就了许 


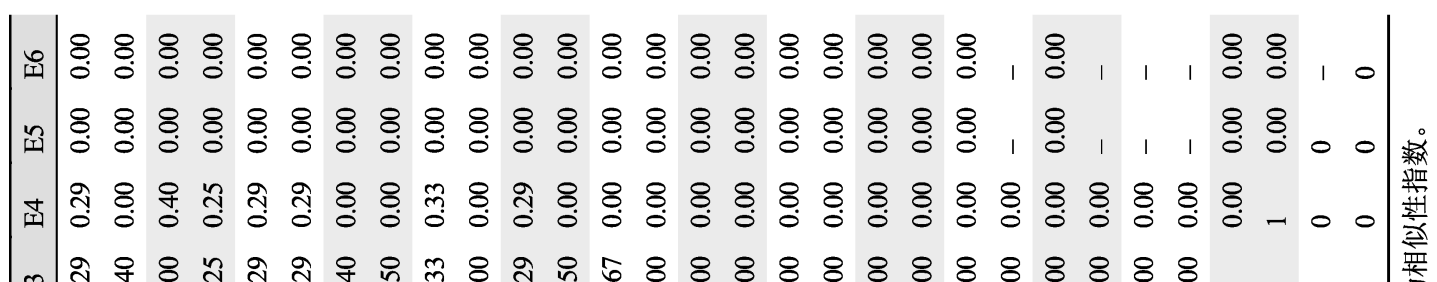
m

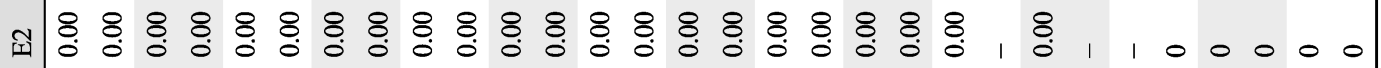

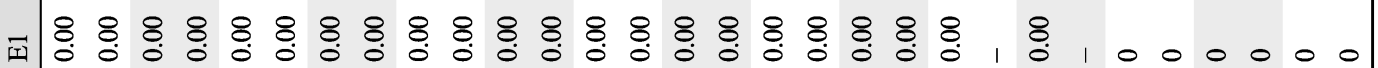

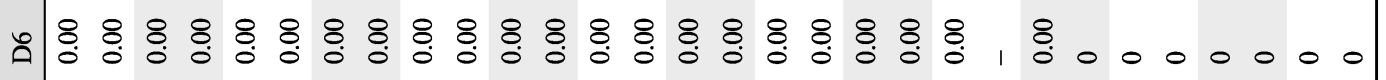

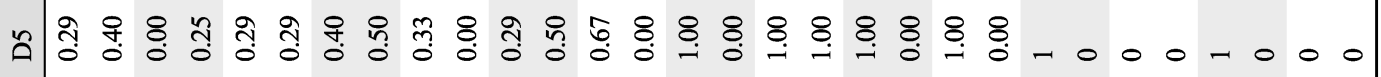
प 

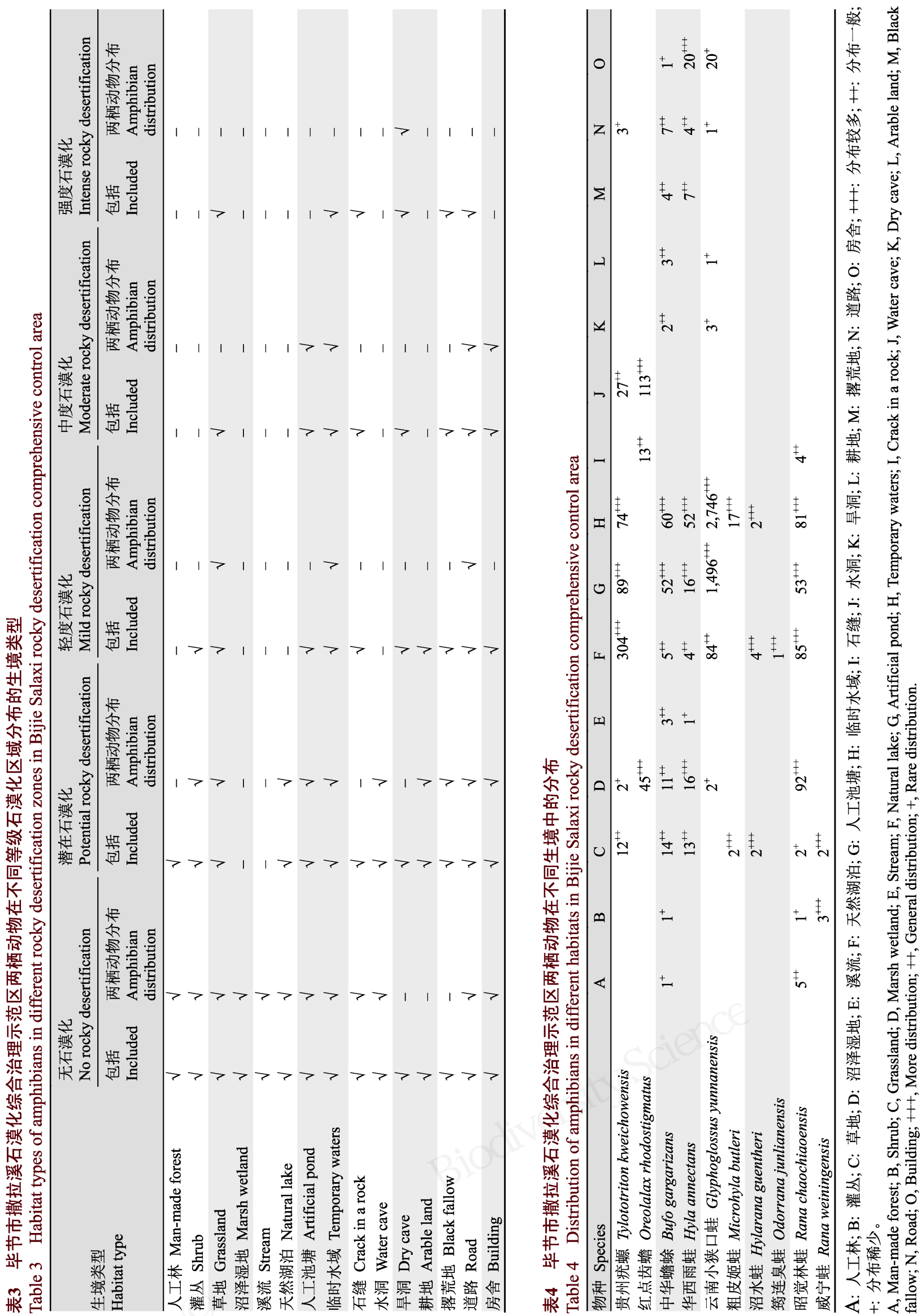

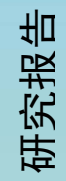


多地下暗河及石灰岩溶洞, 这些都是红点齿蟾良好 的栖息地。而筷连臭蛙和威宁蛙在研究区中较为少 见, 这可能是由于研究区内大型溪流较少, 适合两 种蛙类生存的天然栖息地较为贵乏。调查中, 唯一 一只笉连臭蛙于小溪沟旁的天然湖泊中被发现; 威 宁蛙有3只隐匿于雨后临时径流旁的灌从下, 2 只记 录于一个小型泉点边大石块下的草地中, 这也佐证 了此两种蛙类对于流水环境的偏好性。

10 种两栖动物中, 云南小狭口蛙的个体数多达 4,353只, 占调查总个体数的 $76.53 \%$ 。该蛙个体小, 种群密度高; 变态周期短, 在时间因素上提升了卵 及幼体对外界的抗干扰能力, 因此繁殖能力较强; 且该蛙对于浑浊水体的适应性较强, 而在道路和房 屋的建设中, 形成了大量临时水域和人工池塘, 这 些水体使得云南小狭口蛙成为研究区的优势种。

\section{2 喀斯特石漠化地区两栖动物生境选择差异性}

根据不同等级石漠化区域两栖动物多样性指 数(表1), 无石漠化区域和潜在石漠化区域拥有较高 的多样性和丰富度, 这是由于这两个区域拥有较高 的生境多样性, 不仅水体较多, 且植被覆盖度高、 植被类型多样, 能够充分满足不同两栖动物种类对 于生境的不同要求, 并为其提供庇护、遮阴、攀爬 的媒介; 多种生境类型并存缓解了生境破碎化, 能 有效促进两栖动物种群间的基因交流, 降低种群的 灭绝风险, 并形成物质循环、能量流动和信息传递 的网络, 有利于维持两栖动物群落内部营养系统的 运转。

潜在石漠化区域均匀度指数最低, 主要原因在 于云南小狭口蛙个体小、种群密度高、适生性强, 使 得其在人工池塘和临时水域中个体数量占比相较 于其他物种极度偏高, 而人工池塘和临时水域属于 潜在石漠化区域较为主要的生境类型。

根据两栖动物在不同生境中的分布(表4), 道 路上记录到的4种两栖动物即贵州疮螈、中华蟾蜍、 华西雨蛙和云南小狭口蛙, 均是研究区的优势种及 常见种, 这也从侧面反映了喀斯特石漠化地区人类 活动导致了两栖动物生境的破碎化, 增加了其意外 死亡风险, 不利于两栖动物的保护。

综合而言, 无石漠化区域拥有最为丰富的生境 多样性和最为丰富的两栖动物物种多样性, 潜在石 漠化区域拥有最为丰富的物种多样性及最多的两 栖动物个体数量, 在这两种石漠化等级区域, 其生
态系统的组成异质性和构型异质性都很高。而轻度 石漠化、中度石漠化、强度石漠化区域受人为干扰更 为严重, 其自然生态系统生境条件趋于恶化, 物种 种类组成、群落或系统结构发生改变, 生物多样性 降低(任海等, 2004)。由此可见，石漠化的治理对于 包括两栖动物在内的各种生物生存来说至关重要。

\section{3 喀斯特石漠化地区两栖动物生存现状及保护} 建议

喀斯特地区生态环境容量小, 且石漠化现象呈 不断扩张的态势, 导致喀斯特生态系统发生了大面 积退化(罗中康，2000；彭晚霞等，2008; 宋同清等， 2014), 两栖动物多样性较之其他地区不论种类数 量或是个体数量都较少。由于喀斯特地区特殊的地 表地下二元空间结构, 降水入渗系数高, 导致水源 深埋，因此喀斯特地区地下水资源丰富但地表却水 资源贵乏(袁道先, 2001, 2003; 安吉平等, 2017)。尽 管多雨的季节, 在喀斯特石漠化地区暂时性积水的 坑塘中会有两栖动物在其中产卵繁殖, 但连雨天气 过后，大多数坑塘会逐渐干涸，未孵化的卵以及未 完成变态发育的两栖动物幼体会因缺水而死亡。而 人类对环境的过度开发和利用会成为两栖动物种 群之间交流的障碍，使得生境愈加破碎化，水污染 曼延，进而导致两栖动物死亡、发育和行为异常等 问题。

针对喀斯特石漠化地区两栖动物生存现状, 该地区两栖动物保护可以采取以下措施:

(1)通过各种生物措施、工程措施等对石漠化进 行长久治理，促进两栖动物生境恢复。

(2)构建两栖动物栖息地，例如前期开展的对 原生湿地保护、地势条件较好的暂时性坑塘的防渗 处理等方法都对两栖动物起到了有效的保护作用。 接下来可以基于不同种类两栖动物对生境的不同 偏好进行栖息地构建，也可以从大范围景观尺度上 着手，例如构建两栖动物生态廊道、在道路等基础 设施的规划中融入生态建设理念等。

(3)向当地居民普及生物多样性保护、生态建设 等方面的知识, 做到全民参与, 并在两栖动物集中 生活区域设立警示标志，同时根据两栖动物生活周 期定期对栖息环境进行监测，逢枯水期要对一些渗 漏生境进行水源引流，以确保两栖动物生存环境的 稳定。 


\section{参考文献}

An JP, Wang J, Cai XF, Duan ZB, Yan MM (2017) Research progress of soil loss under the dual structure of southwest karst. Hubei Agricultural Sciences, 56, 1605-1610. (in Chinese with English abstract) [安吉平, 王济, 蔡雄飞, 段 志斌, 颜蒙蒙 (2017) 西南喀斯特二元结构下土壤流失 研究进展. 湖北农业科学, 56, 1605-1610.]

Chen H, Xiong KN, Liu ZB, Qiu J, Chen YB, Xiao SZ, Yang H (2011) Exploration of land consolidation based on biodiversity protection in the Hetou karst area. Earth and Environment, 39, 450-455. (in Chinese with English abstract) [陈许, 熊康宁, 刘忠斌, 邱杰, 陈永毕, 肖时珍, 杨洪 (2011) 基于生物多样性保护的河头喀斯特土地整理探 索. 地球与环境, 39, 450-455.]

Chen JJ, Zhang X, Yang SJ, Xie ZG, Pan CK, Chen JH (2007) Survey on amphibian in Leigongshan Nature Reserve. Sichuan Journal of Zoology, 26, 826-830. (in Chinese with English abstract) [陈继军, 张旋, 杨绍军, 谢镇国, 潘成 坤, 陈继红 (2007) 贵州雷公山自然保护区两栖动物调 查报告. 四川动物, 26, 826-830.]

Dai SG, Zhang JZ, Jiang YM, Xu N (2010) Diversity of amphibian sand reptiles in Baiqing Karst Nature Reserve of Guizhou. Guizhou Science, 28(1), 72-75. (in Chinese with English abstract) [戴诗贵, 张景派, 江亚猛, 徐宁 (2010) 贵州柏箐喀斯特森林自然保护区两栖爬行动物多样性研 究. 贵州科学, 28(1), 72-75.]

Fei L, Hu SQ, Ye CY, Huang YZ (2006) Fauna Sinica • Amphibia (Vol. 1): General Accounts of Amphibia, Gymnophiona and Urodela. Science Press, Beijing. (in Chinese) [费梁, 胡 淑琴, 叶昌媛, 黄永昭 (2006) 中国动物志·两栖纲(第一 卷): 总论, 蚂螈目, 有尾目. 科学出版社, 北京.]

Fei L, Hu SQ, Ye CY, Huang YZ (2009a) Fauna Sinica • Amphibia (Vol. 2): Anura. Science Press, Beijing. (in Chinese) [费梁, 胡淑琴, 叶昌媛, 黄永昭 (2009a) 中国动物志·两 栖纲(第二卷): 无尾目. 科学出版社, 北京.]

Fei L, Hu SQ, Ye CY, Huang YZ (2009b) Fauna Sinica • Amphibia (Vol. 3): Anura, Ranidae. Science Press, Beijing. (in Chinese) [费梁, 胡淑琴, 叶昌媛, 黄永昭 (2009b) 中国 动物志: 两栖纲(第三卷): 无尾目, 蛙科. 科学出版社, 北京.]

Fei L, Ye CY, Jiang JP (2012) Colored Atlas of Chinese Amphibians and Their Distributions. Sichuan Publishing House of Science and Technology, Chengdu. (in Chinese) [费梁, 叶昌媛, 江建平 (2012) 中国两栖动物及其分布 彩色图鉴. 四川科学技术出版社, 成都.]

Feng XJ, Mi XC, Xiao ZS, Cao L, Wu H, Ma KP (2019) Overview of Chinese Biodiversity Observation Network (Sino BON). Bulletin of Chinese Academy of Sciences, 34, 1389-1398. (in Chinese with English abstract) [冯晓娟, 米 湘成, 肖治术, 曹垒, 吴慧, 马克平 (2019) 中国生物多 样性监测与研究网络建设及进展. 中国科学院院刊, 34, 1389-1398.]
Huang J, Liang S, Yin XM, Zhu HM, Wu YJ, Gan XP, Wang ZJ (2016) On amphibian resources of Chishui National Nature Reserve for Alsophila spinulosa. Journal of Southwest China Normal University (Natural Science Edition), 41(4), 64-68. (in Chinese with English abstract) [黄静, 梁盛, 印显明, 朱汉墨, 吴羿锦, 甘小平, 王志坚 (2016) 赤水杪椤国家 级自然保护区两栖动物资源现状. 西南师范大学学报(自 然科学版), 41(4), 64-68.]

Jiang JP, Xie F, Zang CX, Cai L, Li C, Wang B, Li JT, Wang J, Hu JH, Wang Y, Liu JY (2016) Assessing the threat status of amphibians in China. Biodiversity Science, 24, 588-597. (in Chinese with English abstract) [江建平, 谢锋, 藏春金金, 蔡蕾, 李成, 王斌, 李家堂, 王杰, 胡军华, 王燕, 刘畑宇 (2016) 中国两栖动物受威胁现状评估. 生物多样性, 24, 588-597.]

Li B, Zhang W, Shu XX, Mo YM, Pei EL, Yuan X, Wang TH (2017) Distribution characteristic of amphibian in three typical habitats of rural Shanghai. Resources and Environment in the Yangtze Basin, 26, 824-831. (in Chinese with English abstract) [李贲, 张伟, 束潚潇, 莫英敏, 裴恩乐, 袁晓, 王天厚 (2017) 上海郊区三类典型生境的两栖类 分布特征. 长江流域资源与环境, 26, 824-831.]

Li SZ, Lü JC, Li C, Wei G, Xu N (2015) Investigation of herpetological resources in Mayanghe National Nature Reserve, Guizhou, China. Chinese Journal of Zoology, 50, 59-67. (in Chinese with English abstract) [李仕泽, 吕敬才, 李灿, 魏刚, 徐宁 (2015) 麻阳河国家级自然保护区两栖 爬行动物资源调查. 动物学杂志, 50, 59-67.]

Li SZ, Lü JC, Xu N, Wei G (2017) Field survey on amphibians resources in Nangan Nature Reserve of Guizhou, China. Journal of Guiyang University (Natural Sciences), 12(3), 65-69. (in Chinese with English abstract) [李仕泽, 吕敬才, 徐宁, 魏刚 (2017) 德江楠杆自然保护区两栖动物资源 调查. 贵阳学院学报(自然科学版), 12(3), 65-69.]

Luo ZK (2000) Discussion on desertification control and ecological environment construction in karst area of Guizhou Province. Guizhou Environmental Protection Science and Technology, 6(1), 7-10. (in Chinese) [罗中康 (2000) 贵州喀斯特地区荒漠化防治与生态环境建设浅议. 贵州 环保科技, 6(1), 7-10.]

Lü JC, Li SZ, Niu KF, Chen J, Jiang S, Tian Y, Wei G, Xu N (2017a) Amphibian diversity and faunal analysis in Fanjingshan Aational Nature Reserve. Guizhou Agricultural Sciences, 45, 148-152. (in Chinese with English abstract) [吕敬才, 李仕泽, 牛克锋, 陈靖, 姜森, 田宇, 魏刚, 徐 宁 (2017a) 梵净山国家级自然保护区两栖动物多样性及 区系组成. 贵州农业科学, 45, 148-152.]

Lü JC, Zhang HB, Yuan G, Long HW, Guo X, Yu ZG (2017b) Diversity and fauna of amphibians and reptiles in Aha National Wetland Park. Guizhou Science, 35(6), 14-18. (in Chinese with English abstract) [吕敬才, 张海波, 袁果, 龙 汉武, 郭轩, 余志刚 (2017b) 阿哈湖国家湿地公园两栖 爬行动物多样性及区系. 贵州科学, 35(6), 14-18.] 
Ma KP, Liu CR, Liu YM (1995) Measurement of biotic community diversity. II. $\beta$ diversity. Chinese Biodiversity, 3, 38-43. (in Chinese) [马克平, 刘灿然, 刘玉明 (1995) 生物群落多样性的测度方法II. $\beta$ 多样性的测度方法. 生 物多样性, 3, 38-43.]

Ma KP, Liu YM (1994) Measurement of biotic community diversity. I. $\alpha$ diversity (part 2). Chinese Biodiversity, 2, 231-239. (in Chinese) [马克平, 刘玉明 (1994) 生物群落 多样性的测度方法I. $\alpha$ 多样性的测度方法(下). 生物多样 性, 2, 231-239.]

Mouchet F, Cren S, Cunienq C, Deydier E, Guilet R, Gauthier L (2007) Assessment of lead ecotoxicity in water using the amphibian larvae (Xenopus laevis) and preliminary study of its immobilization in meat and bone meal combustion residues. Biometals, 20, 113-127.

Peng WX, Wang KL, Song TQ, Zeng FP, Wang JR (2008) Controlling and restoration models of complex degradation of vulnerable karst ecosystem. Acta Ecologica Sinica, 28, 811-820. (in Chinese with English abstract) [彭晚霞, 王克 林, 宋同清, 曾馥平, 王久荣 (2008) 喀斯特脆弱生态系 统复合退化控制与重建模式. 生态学报, 28, 811-820.]

Ren H, Peng SL, Lu HF (2004) The restoration of degraded ecosystems and restoration ecology. Acta Ecologica Sinica, 24, 1760-1768. (in Chinese with English abstract) [任海, 彭少麟, 陆宏芳 (2004) 退化生态系统恢复与恢复生态 学. 生态学报, 24, 1760-1768.]

Song TQ, Peng WX, Du H, Wang KL, Zeng FP (2014) Occurrence, spatial-temporal dynamics and regulation strategies of karst rocky desertification in Southwest China. Acta Ecologica Sinica, 34, 5328-5341. (in Chinese with English abstract) [宋同清, 彭晚霞, 杜虎, 王克林, 曾馥平 (2014) 中国西南喀斯特石漠化时空演变特征、发生机制与调控 对策. 生态学报, 34, 5328-5341.]

Wang J, Li YL, Li Y, Chen HH, Zeng YJ, Shen JM, Wang YY (2019) Morphology, molecular genetics, and acoustics reveal two new species of the genus Leptobrachella from northwestern Guizhou Province, China (Anura, Megophryidae). ZooKeys, 848, 119-154.

Wang JY, Li JF, Zhang LQ, Zou LL (2012) Prediction of land use structure based on biodiversity conservation. Transactions of the Chinese Society of Agricultural Engineering, 28, 221-226. (in Chinese with English abstract) [王建英, 李江 风, 张丽琴, 邹利林 (2012) 基于生物多样性保护的土地 利用结构预测. 农业工程学报, 28, 221-226.]

Wang YB (2005) Investigation on amphibians in Fokienia hodginsii Nature Reserve, Jinsha and Dafang County, Guizhou. Sichuan Journal of Zoology, 24, 401-402. (in Chinese) [王延斌 (2005) 贵州金沙县、大方县福建柏自然 保护区两栖动物调查. 四川动物, 24, 401-402.]

Wang YB (2010) Survey of amphibians in Lengshuihe Nature Reserve in Guizhou. Guizhou Agricultural Sciences, 38, 191-193. (in Chinese with English abstract) [王延斌 (2010) 贵州金沙冷水河自然保护区两栖动物调查. 贵州农业科
学, 38, 191-193.]

Wei G, Chen FG, Li DJ (1989) Preliminary studies on geographical distribution and faunal regions of amphibians of Guizhou Province. Zoological Research, 10, 241-249. (in Chinese with English abstract) [魏刚, 陈服官, 李德俊 (1989) 贵州两栖动物区系及地理区划的初步研究. 动物 学研究, 10, 241-249.]

Wei G, Xu N, Zhang GF, Tan YM (2007) A survey of amphibians and reptiles in Dashahe Nature Reserve in Guizhou. Sichuan Journal of Zoology, 26, 347-350. (in Chinese with English abstract) [魏刚, 徐宁, 张国防, 谭杨梅 (2007) 贵 州大沙河自然保护区两栖爬行动物多样性研究. 四川动 物, 26, 347-350.]

Wu L, Dong Q, Xu RH (1987) Amphibians of Guizhou. Guizhou People's Publishing House, Guiyang. (in Chinese) [伍律, 董谦, 须润华 (1987) 贵州两栖类志. 贵州人民出版社, 贵阳.]

Xiong KN, Li P, Zhou ZF, An YL, Lü T, Lan AJ (2002) Remote Sensing of Karst Rocky Desertification-GIS Typical Research-Take Guizhou Province as An Example. Geological Publishing House, Beijing. (in Chinese) [熊康 宁, 黎平, 周忠发, 安裕伦, 吕涛, 蓝安军 (2002) 喀斯 特石漠化的遥感-GIS典型研究——贵州省为例. 地质 出版社, 北京.]

Xu N, Dai SG, Zhang JZ (2008) A survey of amphibians in Qingshuihe Nature Reserve of Guizhou. Journal of Guiyang University (Natural Sciences), 3(4), 6-8. (in Chinese with English abstract) [徐宁, 戴诗贵, 张景溷 (2008) 贵州省 清水河风景自然保护区两栖动物调查. 贵阳学院学报(自 然科学版), 3(4), 6-8.]

Yang WK, Zhong WQ, Gao XY (2000) A review of studies on avian habitat selection. Arid Zone Research, 17(3), 71-78. (in Chinese with English abstract) [杨维康, 钟文勤, 高行 宜 (2000) 鸟类栖息地选择研究进展. 干旱区研究, 17(3), 71-78.]

Yao ZM, Qin LJ, Tan CJ, Deng HQ (2018) Research on amphibians' species in Maolan National Nature Reserve, Guizhou. Journal of Guizhou Normal University (Natural Sciences), 36(2), 33-38. (in Chinese with English abstract) [姚正明, 覃龙江, 谭成江, 邓怀庆 (2018) 茂兰国家级自 然保护区两栖类物种多样性研究. 贵州师范大学学报(自 然科学版), 36(2), 33-38.]

Yuan DX (2003) Geological environment and hydroecological problems in karst area. Southern Land Resources, (1), 22-25. (in Chinese) [袁道先 (2003) 岩溶地区的地质环境 和水文生态问题. 南方国土资源, (1), 22-25.]

Yuan DX (2001) World correlation of karst ecosystem: Objectives and implementation plan. Advances in Earth Science, 16, 461-466. (in Chinese with English abstract) [袁道先 (2001) 全球岩溶生态系统对比: 科学目标和执行计划. 地球科学进展, 16, 461-466.]

Zhang YH, Gong DJ, Yan L, Tian G (2012) Study on amphibious reptiles in Taiyang Mountain of Congjiang County in 
Guizhou Province. Journal of Anhui Agricultural Sciences, 40, 194-195. (in Chinese with English abstract) [张永宏, 龚大洁, 问礼, 田果 (2012) 贵州省从江县太阳山两栖爬 行动物研究. 安徽农业科学, 40, 194-195.]

Zhou SC, Meng GT, Yin YX, Yang J, Yu HW, Ren MF, Liu H (2016) Effect of habitat characteristics on the reproductive effort of dybowsky's frogs (Rana Dybowskii) in eastern
Wanda Mountains, Heilongjiang Province. Acta Ecologica Sinica, 36, 2521-2527. (in Chinese with English abstract) [周绍春, 孟根同, 尹远新, 杨娇, 于洪伟, 任梦飞, 刘浩 (2016) 完达山东部林区生境特征对东北林蛙产卵的影 响. 生态学报, 36, 2521-2527.]

\section{(责任编委: 江建平 责任编辑: 黄祥忠)}

\section{附录 Supplementary Material}

\section{附录1 毕节市撒拉溪石漠化综合治理示范区各样方调查时间及物种数}

Appendix 1 Investigation time and species number of quadrat in Bijie Salaxi rocky desertification comprehensive control area http://www.biodiversity-science.net/fileup/PDF/2019351-1.pdf

附录2 毕节市撒拉溪石漠化综合治理示范区两栖动物名录

Appendix 2 List of amphibian species in Bijie Salaxi rocky desertification comprehensive control area http://www.biodiversity-science.net/fileup/PDF/2019351-2.pdf

\section{附录3 毕节市撒拉溪石漠化综合治理示范区15种生境的主要环境特征}

Appendix 3 Main environmental characteristics of various habitats in Bijie Salaxi rocky desertification comprehensive control area http://www.biodiversity-science.net/fileup/PDF/2019351-3.pdf

附录4 毕节市撒拉溪石漠化综合治理示范区不同种类两栖动物在各样方中栖息的生境类型

Appendix 4 The type of habitat in which different kinds of amphibians inhabit in Bijie Salaxi rocky desertification comprehensive control area

http://www.biodiversity-science.net/fileup/PDF/2019351-4.pdf 